\title{
Mediation effect of social skills between impulsivity with substance abuse in adolescents
}

\author{
Mehdi Poorkord $^{\mathrm{a}^{*}}$, Sahar Mirghobad khodarahmi ${ }^{\mathrm{b}}$, Malihe yaghoobzadeh ${ }^{\mathrm{a}}$ and Hasan Rezaee ${ }^{\mathrm{a}}$
}

\begin{tabular}{|c|c|}
\hline CHRON I C LE & ABSTRACT \\
\hline $\begin{array}{l}\text { Article history: } \\
\text { Received January } 18,2013 \\
\text { Received in revised format } \\
8 \text { June } 2013 \\
\text { Accepted } 10 \text { June } 2013 \\
\text { Available online } \\
\text { June } 152013 \\
\text { Keywords: } \\
\text { Impulsivity } \\
\text { Substance abuse } \\
\text { Adolescents } \\
\text { Social skills }\end{array}$ & $\begin{array}{l}\text { The aim of this study is to examine mediation effect of social skills between impulsivity with } \\
\text { substance abuse in adolescents. The research sample consists of } 616 \text { students of vulnerable high } \\
\text { schools in Ardabil City. Together the data of Impulsivity Scale, Matson social skills scale and } \\
\text { substance abuse survey were used [Matson, J. L., Rotatori, A. F., \& Helsel, W. J. (1983). } \\
\text { Development of a rating scale to measure social skills in children: The Matson Evaluation of } \\
\text { Social Skills with Youngsters (MESSY). Behaviour Research and therapy, 21(4), 335-340.]. } \\
\text { The results show that impulsivity indirectly is associated with substance abuse students } \\
(\mathrm{P}<0.001) \text { through the effect on social skills. The results indicate that high levels of impulsivity } \\
\text { and low-level social skills increase substance abuse in students. These results are consistent } \\
\text { with other existing results found in the literature. }\end{array}$ \\
\hline
\end{tabular}

\section{Introduction}

During the past few years, there have been tremendous efforts on investigating the relationship between social skills and impulsivity and their links to crimes among youths (Matson et al., 1983; Howard et al., 1997; Masse \& Tremblay, 1997; Moeller et al., 2001). According to (2000), drug abuse continues to be a major public health problem in the world. Despite the fact that considerable progress has been accomplished on detecting effective prevention methods, there is a large gap between what study has demonstrated to be effective and the methods generally implemented in most schools. The most promising prevention approaches target individuals during the beginning of adolescence and instruct drug resistance skills and norm setting either alone or in combination with general personal and social skills. Evaluation studies testing these techniques demonstrate that they can substantially reduce adolescent tobacco, alcohol, and marijuana use. On the other hand, some studies indicate that these effects may decrease over time, booster interventions have been detected to keep and in some instances even enhance prevention impacts. Some studies have suggested that it could be possible to generate reductions in drug use that last until the end of high school. Available evidence recommends 
that these methods may be effective when taught by various types of teachers and with various populations. Dawe and Loxton (2004) investigated the effect of impulsivity in the development of substance use and eating disorders. Barkin et al. (2002) studied social skills and attitudes associated with substance use behaviors among young adolescents. Epstein et al. (2000) presented a model of smoking among inner-city adolescents by investigating the impact of personal competence and perceived social benefits of smoking.

Donohue et al. (1999) examined substance refusal skills of some 44 conduct-disordered male adolescents where half of the adolescents were dually diagnosed with substance abuse/dependence. They evaluated substance refusal skills utilizing a role-play assessment that consisted of four interpersonal scenarios in which a confederate prompted youths to engage in illicit drug and alcohol activity. The exam showed adequate interrater agreement and validity. Overall skill in refusing alcohol was associated with adolescents' perceptions of belonging and attention, positively and overall skill in refusing illicit drugs was associated with school performance and social competence, positively.

Botvin et al. (2003) investigated the effectiveness of a substance abuse prevention plans in tobacco and alcohol use prevention among elementary school students in grades 3 through 6 . The prevention program thought social resistance skills and general personal and social competence skills. Rates of substance use behavior, attitudes, knowledge, normative expectations, and associated variables were investigated among students. They reported that "intervention students reported less smoking in the past year, higher anti-drinking attitudes, increased substance use knowledge and skills-related knowledge, lower normative expectations for smoking and alcohol use, and higher self-esteem at the posttest assessment, relative to control students".

Botvin and Griffin (2004) provided a review of the theoretical underpinnings of the life skills training (LST) program, along with a description of the program's core components, materials, and methods. They explained that positive behavioral effects of LST on smoking, alcohol, marijuana use as well as the use of multiple substances and illicit drugs, with prevention effects lasting up until the end of high school. According to Brewer and Potenza (2008), Impulse control disorders (ICDs), including pathological gambling, trichotillomania, kleptomania and others, could be conceptualized to lie along an impulsive-compulsive spectrum.

Forys et al. (2007) looked into the participation in specific treatment components predicts alcoholspecific and general coping skills. Hawkins et al. (1992) looked into risk and protective factors for alcohol and other drug problems in adolescence and early adulthood. Moeller et al. (2002) performed an empirical investigation on increased impulsivity in cocaine dependent subjects independent of antisocial personality disorder and aggression. Vassileva et al. (2007) investigated whether all drug addicts impulsive or not by looking into the effects of antisociality and extent of multidrug use on cognitive and motor impulsivity.

The aim of this study is to examine mediation effect of social skills between impulsivity with substance abuse in adolescents. The organization of this paper first presents details of study in section 2 while the results of our investigation are presented in section 3 and concluding remarks are given in the last to summarize the contribution of the paper.

\section{The proposed study}

The aim of this study is to examine mediation effect of social skills between impulsivity with substance abuse in adolescents. The research sample consists of 616 students of vulnerable high schools in Ardabil City. Together the data of Impulsivity Scale, Matson social skills scale and substance abuse survey were used (Matson et al., 1983). Table 1 demonstrates some basic statistics associated with components of the survey. 
Table 1

Basic statistics associated with different components of the questionnaire

\begin{tabular}{|c|c|c|c|c|}
\hline Item & Mean & Standard deviation & Min & Max \\
\hline Social skills & 47.96 & 7.71 & 22 & 66 \\
\hline Non-social skills & 21.23 & 6.39 & 3.63 & 31 \\
\hline Aggression & 33.86 & 6.72 & 11 & 45 \\
\hline Dominance & 13.03 & 3.23 & 4 & 24 \\
\hline Relationship with peers & 23.73 & 4.91 & 6 & 36 \\
\hline Total social skills & 139.82 & 20.50 & 70.22 & 180 \\
\hline Having no plans & 24.07 & 4.57 & 12 & 39 \\
\hline Motor impulsiveness & 21.53 & 5.02 & 11 & 37 \\
\hline Cognitive impulsiveness & 17.72 & 4.10 & 8 & 29 \\
\hline Total impulsiveness & 63.31 & 11.48 & 39 & 99 \\
\hline Drug abuse & 23.11 & 11.14 & 10 & 54 \\
\hline
\end{tabular}

In addition, Table 2 demonstrates the summary of correlation among social skills, impulsiveness and drug abuse.

\section{Table 2}

The summary of correlations among three variables of social skills, impulsiveness and drug abuse

\begin{tabular}{lccc}
\hline Variable & Social skills & Impulsiveness & Drug abuse \\
\hline Social skills & 1 & $-0.633^{* *}$ & $0.515^{* *}$ \\
Impulsiveness & $-0.633^{* *}$ & 1 & $-0.466^{* *}$ \\
Drug abuse & $0.515^{* *}$ & $-0.466^{* *}$ & 1 \\
\hline "** Level of significance $=0.01$ & & &
\end{tabular}

According to the results of Table 2, there is a negative correlation between impulsiveness and social skills $(\mathrm{r}=-0.633$, $\mathrm{P}$-value $=0.000)$, a negative correlation between drug abuse and impulsiveness $(\mathrm{r}=$ 0.466 , P-value $=0.000$ ) and finally there is a positive relationship between drug abuse and social skills $(\mathrm{r}=0.525$, P-value $=0.000)$. Next, we study the role of social skills on relationship between impulsiveness and drug abuse. This could be accomplished through stepwise regression technique, which is presented next.

\section{The results}

In this section, we present details of regression analysis to study the effect of social skill as median factor on relationship between impulsiveness and drug abuse. Table 3 demonstrates the results of our investigation.

Table 3

The summary of stepwise regression technique

\begin{tabular}{|c|c|c|c|c|c|c|}
\hline & $\begin{array}{c}\text { Non-standard values } \\
\text { B }\end{array}$ & Standard error & $\begin{array}{c}\text { Standard coefficient } \\
\beta \\
\end{array}$ & $\mathrm{t}$ & P-Value & $\mathrm{R}$ \\
\hline Intercept & -8.513 & 2.16 & & -3.94 & $<0.001$ & \\
\hline Impulsiveness & 0.499 & 0.034 & 0.515 & 14.875 & $<0.001$ & 0.52 \\
\hline Social skills & -0.121 & 0.024 & -0.234 & -5.346 & $<0.001$ & 0.55 \\
\hline
\end{tabular}

As we can observe from the results of Table 3, when the median variable is entered into the model, the effect of social skills is still meaningful, which confirm the results of our survey. Therefore, we can confirm the hypothesis of the survey, i.e. social skills can be a median factor for the relationship between impulsiveness and drug abuse.

\section{Conclusion}

In this paper, we have performed an investigation on the effect of social skills as a median factor on relationship between impulsiveness and drug abuse. The study was performed on some selected high 
schools students in city of Ardebil, Iran and using stepwise regression technique, the study has confirmed this relationship. In addition, the results of our survey have confirmed that having no plans, motor impulsiveness and cognitive impulsiveness had positive relationship with drug abuse. The results of our survey have confirmed that there was a negative correlation between impulsiveness and social skills $(\mathrm{r}=-0.633$, P-value $=0.000)$, a negative correlation between drug abuse and impulsiveness $(\mathrm{r}=-0.466, \mathrm{P}$-value $=0.000)$ and finally there was a positive relationship between drug abuse and social skills $(\mathrm{r}=0.525, \mathrm{P}$-value $=0.000)$.

\section{References}

Barkin, S. L., Smith, K. S., \& DuRant, R. H. (2002). Social skills and attitudes associated with substance use behaviors among young adolescents. Journal of Adolescent Health, 30(6), 448-454.

Botvin, G. J. (2000). Preventing drug abuse in schools: Social and competence enhancement approaches targeting individual-level etiologic factors. Addictive Behaviors, 25(6), 887-897.

Botvin, G. J., Griffin, K. W., Paul, E., \& Macaulay, A. P. (2003). Preventing tobacco and alcohol use among elementary school students through life skills training. Journal of Child \& Adolescent Substance Abuse, 12(4), 1-17.

Botvin, G. J., \& Griffin, K. W. (2004). Life skills training: Empirical findings and future directions. Journal of Primary Prevention, 25(2), 211-232.

Brewer, J. A., \& Potenza, M. N. (2008). The neurobiology and genetics of impulse control disorders: relationships to drug addictions. Biochemical pharmacology, 75(1), 63-75.

Dawe, S., \& Loxton, N. J. (2004). The role of impulsivity in the development of substance use and eating disorders. Neuroscience \& Biobehavioral Reviews, 28(3), 343-351.

Donohue, B., Van Hasselt, V. B., Hersen, M., \& Perrin, S. (1999). Substance refusal skills in a population of adolescents diagnosed with conduct disorder and substance abuse. Addictive behaviors, 24(1), 37-46.

Epstein, J. A., Griffin, K. W., \& Botvin, G. J. (2000). A model of smoking among inner-city adolescents: The role of personal competence and perceived social benefits of smoking. Preventive medicine, 31(2), 107-114.

Forys, K., McKellar, J., \& Moos, R. (2007). Participation in specific treatment components predicts alcohol-specific and general coping skills. Addictive behaviors, 32(8), 1669-1680.

Hawkins, J. D., Catalano, R. F., \& Miller, J. Y. (1992). Risk and protective factors for alcohol and other drug problems in adolescence and early adulthood: implications for substance abuse prevention. Psychological bulletin, 112(1), 64.

Howard, M. O., Kivlahan, D., \& Walker, R. D. (1997). Cloninger's tridimensional theory of personality and psychopathology: applications to substance use disorders. Journal of Studies on Alcohol and Drugs, 58(1), 48.

Masse, L. C., \& Tremblay, R. E. (1997). Behavior of boys in kindergarten and the onset of substance use during adolescence. Archives of general psychiatry,54(1), 62.

Matson, J. L., Rotatori, A. F., \& Helsel, W. J. (1983). Development of a rating scale to measure social skills in children: The Matson Evaluation of Social Skills with Youngsters (MESSY). Behaviour Research and therapy, 21(4), 335-340.

Moeller, F. G., Dougherty, D. M., Barratt, E. S., Schmitz, J. M., Swann, A. C., \& Grabowski, J. (2001). The impact of impulsivity on cocaine use and retention in treatment. Journal of substance abuse treatment, 21(4), 193-198.

Moeller, F. G., Dougherty, D. M., Barratt, E. S., Oderinde, V., Mathias, C. W., Harper, R. A., \& Swann, A. C. (2002). Increased impulsivity in cocaine dependent subjects independent of antisocial personality disorder and aggression. Drug and alcohol dependence, 68(1), 105-111.

Vassileva, J., Gonzalez, R., Bechara, A., \& Martin, E. M. (2007). Are all drug addicts impulsive? Effects of antisociality and extent of multidrug use on cognitive and motor impulsivity. Addictive Behaviors, 32(12), 3071-3076. 